\title{
Research on the Test Development of Speculative Expression Based on Speculative Reading
}

\author{
Lijun Yang ${ }^{1}$ and Lei Yang ${ }^{1, *}$
}

\author{
${ }^{1}$ School of Chinese Language and Literature, Beijing Normal University, 100875, Beijing \\ *Corresponding author. Email: 202131080002@mail.bnu.edu.cn
}

\begin{abstract}
Based on the requirements of the "speculative reading and expression" task group in the high school Chinese curriculum standards, and based on the theoretical interpretation of "combination of reading and writing", the important value and value of speculative writing and expression based on speculative reading are clarified. Basic connotation, analyze the proposition characteristics of speculative reading and writing in the evaluation of Chinese examination, explore the development direction of speculative expression propositions based on speculative reading, propose that the connection between reading content and expression content should be emphasized, and create rich and diverse speculative expression situations, Strengthen the propositions and suggestions of the relevance of reading content and social life, and achieve effective evaluation of speculative reading and writing skills.
\end{abstract}

Keywords: Speculative reading, Speculative expression, Chinese, Test evaluation

\section{INTRODUCTION}

The announcement and re-revision of the 2017 version of the high school curriculum standards put "speculative reading and expression" as an important curriculum content of high school Chinese, and it is correct, and the innovation of the curriculum content also puts forward new requirements and challenges for examination evaluation. Traditional Chinese courses and Chinese test evaluation have long focused on individual composition writing ability, ignoring the development and examination of writing ability combined with reading and writing; longterm attention has been paid to the analysis and interpretation of the effect of expression on reading comprehension, and neglecting the cultivation of writing speculative ability based on reading comprehension And examination; long-term attention to literary text writing, ignoring the training and examination of speculative text writing ability, followed by problems such as separation of reading and writing, difficulty in improving writing ability, and insufficient development of speculative ability. In order to change this phenomenon, this research attempts to find a breakthrough for improving writing ability from speculative expression. The requirements of the "speculative reading and expression" task group in the high school Chinese curriculum standards are the starting point, and the theoretical interpretation of "combination of reading and writing" is the starting point. According to the basis, it is clear that the important value and basic connotation of speculative writing and expression based on speculative reading are analyzed, the reform trend of speculative writing in Chinese examination evaluation is analyzed, and the development direction and effective strategies of speculative expression propositions based on speculative reading are explored.

\section{SPECULATIVE READING AND SPECULATIVE EXPRESSION}

\begin{abstract}
"Speculative reading" and "speculative expression" are a group of closely related important concepts. To correctly understand the relationship between the two, you can experience speculative reading and speculative reading from the definition of the basic connotation in the top-level design of the curriculum standards The common characteristics of sexual expression, through the interpretation of the internal logic of the comprehensiveness and integrity of the language learning task group, to understand the symbiotic relationship between speculative reading and speculative expression. Finally, we look for speculative reading and speculative reading from the perspective of different theoretical systems. The theoretical basis of speculative expression is highly integrated, so as to explore the rationality and importance of speculative expression training based on speculative reading.
\end{abstract}

\subsection{The Basic Connotation of "Speculative Reading" And "Speculative Expression"}

As one of the learning task groups of compulsory courses designed by the 2017 general high school curriculum standards, the task group "Speculative Reading and Expression" plays an important role in the Chinese curriculum of high school. The objectives and content of this task group are described in the curriculum standards as: 
(1) Read ancient and modern Chinese and foreign essays, grasp the author's views, attitudes, and language characteristics, and understand the author's method and logic of expounding opinions. Read recent important current affairs reviews, and learn the author's position, viewpoints, and methods of commenting on major domestic and foreign issues or social hot issues. When reading various texts, analyze and question, interpret multiple interpretations, and cultivate the ability to think.

(2) Learn to express and elucidate one's own opinions, strive to make correct arguments, accurate language, appropriate arguments, and be logical. Learn to think about problems from multiple angles. Learn to refute, be able to be justified and persuade people with reason.

(3) Carry out discussions and debates around topics of interest, express their opinions rationally and methodically, discuss on an equal footing, and argue in a targeted, polite, and polite manner.

From the above expressions, we can find that "speculative reading and expression" includes two aspects: speculative reading and speculative expression.[1] The first article of goals and content points to speculative reading, pointing out that the content of speculative reading is a famous commentary. And current affairs commentary emphasizes the cultivation of speculative ability through reading this type of text; Articles 2 and 3 point to written expression and discussion and argument, emphasizing the use of speculative ability in the process of diversified expression. The relationship between the two is a chain process from training to application.

\subsection{The Internal Logic of "Speculative Reading and Expression" from the Perspective of Task Groups}

In the above definition of connotation, we understand the task group of "speculative reading and expression" from two aspects, but at the same time, we must also realize that "speculative reading" and "speculative expression" are in the actual implementation process. China cannot be separated. From the perspective of thinking development, on the one hand, the speculativeness of reading needs to be presented through written or oral expression. On the other hand, the purpose of reading in this task group is to improve thinking ability, and then use this thinking ability In all kinds of practical expression activities and real situations, as some scholars have mentioned, in the teaching of "speculative reading", "the activity of'speculative expression' is always present."[2] From the perspective of the internal logic of the task group, each learning task group is a Chinese course content system that integrates context, content, methods and resources. [3] It is "task-oriented, learning projects as the carrier, and integration of learning context and learning content. , Learning methods and learning resources to guide students to improve their language literacy in the process of using language" "Pursue the comprehensive effect of language, knowledge, skills, thoughts and feelings, cultural accomplishment and other aspects, multi-level goal development, rather than subject knowledge." Point'Analysis, simple linear arrangement and connection of subject-by-subject skill training."[4] Therefore, "speculative reading and expression" is by no means divided into two learning systems, but a complete system, whether it is speculative reading and writing. The teaching process, or the examination and evaluation of speculative reading and writing, cannot be carried out completely in isolation.

\subsection{The Theoretical Basis for Speculative Reading and Writing in the Context of "Combination of Reading and Writing"}

The concept of "combination of reading and writing" is not unfamiliar in Chinese teaching. In recent years, many discussions and practices have been carried out in the field of Chinese teaching around the combination of reading and writing. Mr. Ye Shengtao once pointed out: "Reading is absorption and writing is pour." [5] Mr. Zhang Zhigong believes : "Only when the use of language (writing) is built on the basis of language absorption (reading), can the greatest effect be achieved." [6] The constructivist view believes that reading and writing are the construction, modification and formation of meaning. We can often complete the reader-author role exchange and resultprocess alternation in the process of reading and writing. Reading and writing are in the "meaning" Blending in "construction" means that the subject of learning becomes the explorer, discoverer and creator of meaning in the integration of reading and writing.[7] Cognitive psychology believes that reading and writing activities share the physiological structure of the same area of the brain, so reading and writing contain common knowledge elements, that is "shared knowledge",[8] which includes metacognition, domain knowledge, knowledge of general text characteristics, and procedural knowledge and skills. [9]This theory believes that reading and writing have similar strategies, and it is necessary to create a real situation, promote the mutual connection of reading and writing, and provide space and freedom for a wide range of reading and free expression. It can be seen that the combination of reading and writing can take care of the overall development of Chinese language and literature literacy, and can have a positive effect on the improvement of reading and writing skills

\section{THE PROPOSITIONAL CHARACTERISTICS OF SPECULATIVE READING AND WRITING IN HIGH SCHOOL CHINESE EXAMINATIONS}

The language test should support students to reasonably express their opinions on autonomous knowledge and critical thinking, pay attention to assessing the logic and 
rationality of students' thinking processes, and emphasize critical thinking, individualized development and innovative abilities.[10] Looking at the current high school Chinese examination evaluation system, the characteristics of evaluation lagging behind the course objectives are also reflected in speculative reading and writing. Although the curriculum standards determine "speculative reading and expression" as one of the required courses, the examination evaluation has not been provided. The dedicated space is used to test students' speculative reading and writing skills. The original examination and evaluation method of reading and writing separation is still used. The examination of speculative reading focuses on the integration of information and the correctness of the answer, and the examination of speculative expression is mainly Focusing on the "big composition" test questions, taking the 7 sets of national college entrance examination questions in 2019 as an example, only the Beijing paper involves "micro writing", that is, students are required to write short, practical paragraphs, and most of them are combined with the reading of classics test.[11]

\subsection{Focus on Content Interpretation and Neglect Logical Reasoning}

The combined examination of micro-writing and classic reading is an important examination trend in recent years. The combination of speculative reading and writing in the entire book reading teaching also has a positive effect. However, the original intention of "speculative reading and expression" in the curriculum standards is reading theory Famous articles and current affairs reviews. Therefore, in the process of examination, because the famous works themselves do not have the strong logic of the famous articles and current affairs reviews, micro-writing often examines the students' in-depth exploration and interpretation of the content and thoughts of the famous books. Focusing on students' thinking ability, students may pay attention to the ideological core of masterpieces through the accumulation and integration of various angles and historical and cultural background, but in the final analysis it is not a concentrated expression of personal thinking ability, and its analysis and expression may even be jumpy and lack logic Sexual discourse. Not only that, influenced by structuralist theories, teachers' teaching often stays at the level of text interpretation, mostly shallow deconstruction and understanding of words, sentences, and lack of an overall review of the internal logic and associations of the text, thus ignoring the "implied readers, author's role, subject" and other information.[12]

\subsection{Emphasize Information Integration and Neglect Development of Thinking}

Incorporating speculative expression into the essay text reading test questions is an important way to realize speculative reading and the evaluation of expressive ability. However, looking at the evaluation of high school language examinations in recent years, we find that the specific ability points of the discourse text test are nothing more than handsome selection and integration of the information in the text, analyzing the structure of the article, summarizing the main points of the content, summing up the central meaning, analyzing the arguments, arguments and methods of argumentation.[11] The analysis summarizes the author's views and attitudes in the text. Although it includes the analysis of textual arguments, arguments, and argumentation methods, it also examines the refinement and analysis of the author's views and attitudes in the text. In the final analysis, the method of examination is only the integration of textual information. It examines the ability of students to construct and use language. Students have no space for individualized expression, and cannot comprehensively use the speculative experience formed during the reading process to transfer to a certain problem or phenomenon. Use, to put forward your own thinking and judgment, and use reasonable arguments to demonstrate, and then achieve the training goal of thinking development and promotion.

\subsection{Emphasize Written Writing Less Oral Expression}

Through analyzing the curriculum standards, we find that speculative expression includes two aspects: written expression and discussion and argumentation. Current propositions tend to be more inclined to the former, focusing only on students' writing ability and lack of examination and argumentation ability. From the perspective of students' composition psychology, this single form of writing is likely to cause students to be confined in a "self-talking" space for a long time. Writing has no real context and reading objects. Writing naturally lacks enthusiasm and appeal. Make a comment farfetched.[13] This phenomenon is firstly caused by the neglect of oral expression in traditional Chinese teaching, and secondly, it is caused by the limitation of the oral expression ability of the pen-and-paper test. In fact, the importance of oral expression is self-evident, and the limitations of the paper-and-pencil test on oral expression ability can also be achieved through changes in test content and question types, such as creating a variety of real situations, including writing debates, Speech drafts, etc., allow students to present the thought process of oral expression in writing.

On the whole, the combination of speculative reading and expression in the current high school Chinese test propositions is fragmented and one-sided, and lacks systematic design and formal innovation. 


\section{SUGGESTIONS FOR SPECULATIVE EXPRESSION PROPOSITIONS BASED ON SPECULATIVE READING}

It is worthy of affirmation that the current concept and strategy of language test proposition are changing. For example, attention is paid to speculative reading and writing ability, and micro-writing is consciously integrated into the reading of classics, etc., all of which will evaluate the future speculative reading and expression task groups. Has a positive predictive effect. To further integrate speculative expression based on speculative reading into the test propositions, one must pay attention to the ability of speculative expression to be examined. The following three abilities will be the ability to express individual views, the ability to think from multiple angles, and the ability to participate in a wide range of society. Starting from the main points, put forward specific suggestions for the test question system:

\subsection{The Ability to Express Individual Views: Attach Importance to the Perspective Conversion of Reading and Expression}

The curriculum standard points out that it is necessary to "learn to express and interpret one's own views, strive to make correct arguments, accurate language, appropriate arguments, and be logical." It can be seen that the ability to express individualized views is the primary concern for the ability to express speculatively. Therefore, when expressing test questions in speculative reading, you should choose famous essays and current affairs comments as much as possible to guide students to understand the author's method and logic of expounding opinions. At the same time, attention should be paid to changing students' passive reading and absorbing perspectives into active construction and expression perspectives. It is not only simple repetition and extraction of text content, but also sets the topic of personal opinion statement, provides personalized expression opportunities, and allows students to Focusing on the same topic or related topics, put forward personal opinions outside the reading text, and make full use of the expression methods learned in reading and the discussion methods accumulated in daily life, and select appropriate arguments for logical expression.

\subsection{Multi-angle Thinking Ability: Create Rich and Free Speculative Expression Situations}

The curriculum standard points out that it is necessary to "learn to think about problems from multiple angles. Learn to refute, be able to be well-founded, and persuade people with reason." This requirement is in fact a benchmark for oral expression ability, which tests students' ability to deal with a variety of practical problems. Ability to actively switch perspectives and think. Therefore, in the preparation of test questions, it is possible to design multiple different scenarios in a question, guide students to think about the same problem from different angles, follow different ideas to demonstrate and reason, and form through the thinking of opposing viewpoints. A rigorous thinking process, so as to refute the opinions that they have proved wrong or disagree with, and use a scientific and rational logical system to support their claims and express their opinions

\subsection{Extensive Social Participation Ability: Strengthen the connection between reading Content and Social Life}

The curriculum standard points out that it is necessary to "conduct discussions and debates around topics of interest." "Topics of interest" actually narrow the relationship between written materials and students' daily lives. It focuses on students' participation in social life and participation. Public reasoning, the ability to discuss or debate around the topic of social life. In the final analysis, our education is to cultivate modern citizens who have the ability to use spoken and written language to communicate normally.[14] At the same time, the combination of reading and writing needs to set up specific, real and vivid life situations for students, help students construct reading and writing schemas,[15] and cultivate the ability to solve reallife problems. Only by developing a conscious sense of reasoning and reasoning habits, and continuously improving the ability of reasoning, can we gain a foothold in personal life and social communication. Therefore, the proposition of the test questions should not only be based on the text, but also be transferred to the areas that may be involved in social life, requiring students to discuss or debate on a topic or hot issue in a certain social environment and living environment, and combine current affairs comments with discussion and debate Together.

\section{CONCLUSION}

Whether it is a highly integrated learning task group or a speculative reading and writing that emphasizes the development and improvement of thinking, all of them put forward new requirements for the reform of high school language examination evaluation, change the single writing evaluation mode, and promote speculative expression and speculative reading The in-depth integration of the syllabus will further explore how to construct an examination evaluation system that matches the curriculum objectives, which ability elements should be paid attention to in the speculative expression based on speculative reading, which aspects should be examined, and what content and form of speculative expression test questions should be formulated , Is an important topic for the propositions of speculative reading and expression task groups in the future. Constantly reviewing the propositional characteristics of the test evaluation, discovering the shortcomings and deficiencies of the test evaluation, grasping the 
development trend of the speculative reading and writing test evaluation, has an important baton role in promoting the improvement of students' thinking ability

\section{REFERENCES}

[1] Lu Zhiping, Zhang Kezhong. Understanding and Implementation of the Task Group of "Speculative Reading and Expression"[J].Language Construction,2019(03):4-8.

[2]Shaylu. Construction of the implementation path of the "speculative reading and expression" learning task group[D]. East China Normal University, 2019.

[3]Wu Xinxin. Learning Task Group: Reconstruction of High School Chinese Curriculum Content[J].Educational Science Research,2018(11):7681.

[4]Ministry of Education of the People's Republic of China: General High School Chinese Curriculum Standards (2017 edition revised in 2020) [S]. Beijing: People's Education Press, 2020.

[5]Ye Shengtao. Ye Shengtao Chinese Education Essays [C]. Jiang Zhongren, Du Caoyong, eds. Beijing:

Education Science Press, 1980.

[6]Zhang Zhigong. Collection of Chinese Teaching Theory [M]. Fuzhou: Fujian Education Press, 1980.

[7]Li Jinyun, Li Shengli. The "Combination of Reading and Writing" in the Horizon of Deep Learning:

Theoretical Explanation and the Core of

Teaching $[\mathrm{J}]$.Course.Textbook.Teaching

Method,2020,40(07):79-85.
[8] Li Benyou.A Comparative Study on the Construction of the Combination Path of Reading and Writing in China and the United

States[J].Courses'Textbook $\cdot$ Teaching Method,2012,32(10):116-120.

[9] Jill Fitzgerald,Timothy Shanahan.Reading and writing Relations and Their Development[J].

Educational Psychologist,2000(1).

[10]Li Qian. Research on the core literacy-based senior high school Chinese examination questions[J].China Examinations,2018(10):14-19.

[11]Zheng Guomin, Tan Xia, Wang Xuanrui. Research Report on Chinese Test Questions for National High School Entrance Examination in 2019 (College Entrance Examination) $[\mathrm{M}]$. Beijing: Beijing Normal University Press, 2020:292-293,118.

[12]Raimes A.Techniques in Teaching Writing[M].New York:Oxford University Press, 1983:123.

[13]Zhu Xinhua. Develop composition teaching reform from the perspective of students' composition psychology[J].Curriculum.Textbook.Teaching Method,2001(03):20-24.

[14]Zheng Guomin. Thoughts on the reform of the Chinese course in the nine-year compulsory education in my country[J].Curriculum.Textbook.Teaching Method,2000(10):3-7.

[15]Taffy E Raphael,Carol Sue Englert. Integrating Writing and Readi ng Instruction[J]Basal Reading,1988(4). 